\title{
Heregulin, a new interactor of the telosome/shelterin complex in human telomeres
}

\author{
Javier A. Menendez ${ }^{1,2, *}$, Louisa Benboudjema ${ }^{3, *}$, Luciano Vellon ${ }^{4}$, Miguel A. Rubio ${ }^{5}$, \\ Ingrid Espinoza ${ }^{6,7}$, Judith Campisis, ${ }^{8,9}$ and Ruth Lupu ${ }^{10,11}$ \\ ${ }^{1}$ ProCURE (Program Against Cancer Therapeutic Resistance), Metabolism \& Cancer Group, Catalan Institute of Oncology \\ (ICO), Girona, Spain \\ ${ }^{2}$ Girona Biomedical Research Institute (IDIBGI), Girona, Spain \\ ${ }^{3}$ Evanston Northwestern Healthcare Research Institute, Evanston, IL, USA \\ ${ }^{4}$ IBYME, CONICET-Laboratorio de Immunohematología, Buenos Aires, Argentina \\ ${ }^{5}$ Laboratory of Hematology Service, Institut d'Investigació Biomèdica Sant Pau, Hospital de la Santa Creu i Sant Pau, \\ Barcelona, Spain \\ ${ }^{6}$ Department of Biochemistry, University of Mississippi, Jackson, MS, USA \\ ${ }^{7}$ Cancer Institute, University of Mississippi, Jackson, MS, USA \\ ${ }^{8}$ Lawrence Berkeley National Laboratory, Life Sciences Division, Berkeley, CA, USA \\ ${ }^{9}$ Buck Institute for Research on Aging, Novato, CA, USA \\ ${ }^{10}$ Mayo Clinic, Department of Laboratory Medicine and Pathology, Division of Experimental Pathology, Rochester, MN, USA \\ 11 Mayo Clinic Cancer Center, Rochester, MN, USA \\ * These authors have contributed equally to this work \\ Correspondence to: Ruth Lupu, email: Iupu.ruth@mayo.edu
}

Javier A. Menendez, email: jmenendez@iconcologia.net

Keywords: heregulin, telomere, telosome, shelterin complex, TRF2

Received: June 27, $2015 \quad$ Accepted: July 10, $2015 \quad$ Published: July 22, 2015

This is an open-access article distributed under the terms of the Creative Commons Attribution License, which permits unrestricted use, distribution, and reproduction in any medium, provided the original author and source are credited.

\section{ABSTRACT}

Telomere length, shape and function depend on a complex of six core telomereassociated proteins referred to as the telosome or shelterin complex. We here demonstrate that the isoform $\beta 2$ of the heregulin family of growth factors (HRGB2) is a novel interactor of the telosome/shelterin complex in human telomeres. Analysis of protein-protein interactions using a high-throughput yeast two-hybrid (Y2H) screen identified RAP1, the only telomere protein that is conserved from yeasts to mammals, as a novel interacting partner of HRG $\beta 2$. Deletion analysis of RAP1 revealed that the linker domain, a region previously suggested to recruit negative regulators of telomere length, interacts specifically with HRG 32 . Co-immunoprecipitation and imaging experiments demonstrated that, in addition to RAP1, HRG 32 could associate with the RAP1-associated telomeric repeat binding factor 2 (TRF2). Deletion analysis of HRG $\beta 2$ confirmed that a putative nuclear localization signal (NLS) was necessary for nuclear HRG $\beta 2$ to exert a negative regulation of telomere length whereas the $\mathbf{N}$-terminus (extracellular) amino acids of HRG 32 were sufficient to interact with RAP1/TRF2 and promote telomere shortening. Taken together, our studies identify nuclear HRG $\beta 2$ as one of the previously unknown regulators predicted to be recruited by the RAP1 linker domain to negatively regulate telomere length in human cells. Our current findings reveal that a new, but likely not the last, unexpected visitor has arrived to the "telosome/shelterin town". 


\section{INTRODUCTION}

Telomeres are specialized DNA-protein complexes found at the ends of eukaryotic linear chromosomes that provide protection from degradation, fusion, and recombination $[1,2]$. Telomere homeostasis requires the cooperation between the DNA polymerase, telomerase, and an array of telomere end-binding factors including TRF1, TRF2, TIN2, RAP1, TPP1, and POT1. This complex, formed by multiple telomeric proteins with exquisite specificity for the arrays of telomerase-added TTAGGG repeats at chromosome ends, is known as the telosome or shelterin complex [3, 4]. Given the variety of functions that the telosome/shelterin complex performs, it is anticipated that the number of its affiliated factors will increase [3-5]. Accordingly, this complex of six core DNA-binding proteins and their sub-complexes serve as basic building blocks from which diverse signaling pathways originate through coordination of proteinprotein interactions and protein complex cross-talk on the telomeres, the so-called telomere "interactome" [6-8].

The heregulin (HRG) family of growth factors comprises 15 distinct isoforms originating from alternative RNA splicing of HRG1, HRG2, HRG3, and HRG4 genes. HRG plays an important role in human cancer through its conventional paracrine or autocrine ability to bind and activate the HER-2/-3/-4 (erbB-2/-3/-4) tyrosinekinase cell surface receptors [9-13]. Focusing on the isoform $H R G \beta 2$, our previous studies in mice have shown that HRG $\beta 2$ overexpression, independent of estrogen stimulation or high levels of the HER2 (erbB-2) oncogene, is sufficient for the generation of adenocarcinomas while favoring the metastatic spread of breast cancer (BC) cells $[14,15]$. Conversely, antisense blockade of HRG $\beta 2$ expression efficiently inhibits tumorigenesis and metastasis in BC cells [16]. Therefore, HRG $\beta 2$ can exclusively promote cell malignant transformation, tumorigenicity and metastasis. Moreover, HRG $\beta 2$ can differentially modulate $\mathrm{BC}$ cell responses to DNAdamaging drugs. Accordingly, forced expression of HRG $\beta 2$ promotes cancer cell hypersensitization to the anthracycline antibiotic doxorubicin while inducing resistance to the alkylating agent cisplatin [17-19]. Interestingly, some HRGs have been shown to translocate to the nucleus in cancer cells, strongly suggesting that the activity HRG $\beta 2$ is not confined to the initiation of surface receptor-mediated signaling [18, 20-23]. It is not clear, however, which functions of HRG $\beta 2$ are exclusively dependent on the activation of erbB receptors, which can be solely attributed to its nuclear compartmentalization, and which HRG $\beta 2$ domains might serve to link a distinct sub-cellular localization of HRG $\beta 2$ with a given function in cancer cells.

Using the yeast two-hybrid (Y2H) system as a highthroughput platform for interactomics, we here aimed to investigate HRG $\beta 2$ protein-interaction networks. Using the classical screen to search for pairwise interactions between HRG $\beta 2$ and putative interaction partners present in a human mammary gland cDNA library, we provide the first demonstration that HRG $\beta 2$ is a novel interactor of the telosome/shelterin complex that connects the linker domain of repressor-activator protein 1 (RAP1) [24], a region suggested to recruit negative regulators of telomere length, with the RAP1-associated factor TRF2 [24-27].

\section{RESULTS}

\section{Yeast two-hybrid screening reveals an association between HRG $\beta 2$ and the telomeric protein RAP1}

To identify new protein interacting partners of HRG $\beta 2$, we fused cDNA corresponding to the full-length coding sequence of human HRG $\beta 2$ to the GAL4-DNABinding Domain (GAL4-DBD) in pGBKT7 as bait in the $\mathrm{Y} 2 \mathrm{H}$ system to screen a human mammary gland cDNA library. From a total of 35 positive transformants, only two transformants included open reading frames (ORFs) for known genes. Strikingly, both candidates were found to encode for telomere-related proteins. Positive clone \#415 contained DNA coding for amino acid residues 116-221 at the C-terminal serine/arginine-rich domain of SC-35 (gi:33875326), a human splicing factor that has been detected in close proximity to telomeres [28]. Positive clone \#480 contained a $1.2 \mathrm{~kb}$ insert. Amplification of this insert by 5 -RACE resulted in a cDNA fragment encoding amino acid residues 127-259 of RAP1 (gi:8102032; Fig. 1A), a negative regulator of telomere length that specifically interacts with the telomere-associated protein TRF2 [3, 24-27, 29, 30].

In light of these observations and because of our recent novel finding that HRG $\beta 2$ is a new regulator of telomere length, likely through its ability to regulate and interact with TRF2 and RAP1 [31], we undertook a systematic approach to better understand the role of HRG $\beta 2$ at the telosome/shelterin complex in human telomeres. To confirm the direct interaction between HRG $\beta 2$ and RAP1, we transformed yeast with the full-length HRG $\beta 2$ ORF in the pGADT7 vector and a pACT2 plasmid expressing the full length RAP1 cDNA. Significant yeast growth was observed in plates containing selection medium (data not shown) indicating of an interaction between HRG $\beta 2$ and RAP1, and transformants were positive in the $\beta$-galactosidase assay (Fig. 1B).

\section{The linker domain of RAP1 mediates the interaction between RAP1 and HRG 32}

RAP1 contains four distinct functional domains: a BRCT domain, a Myb HTH motif, a coiled region, and a C-terminal protein interaction domain (termed RCT). 
A

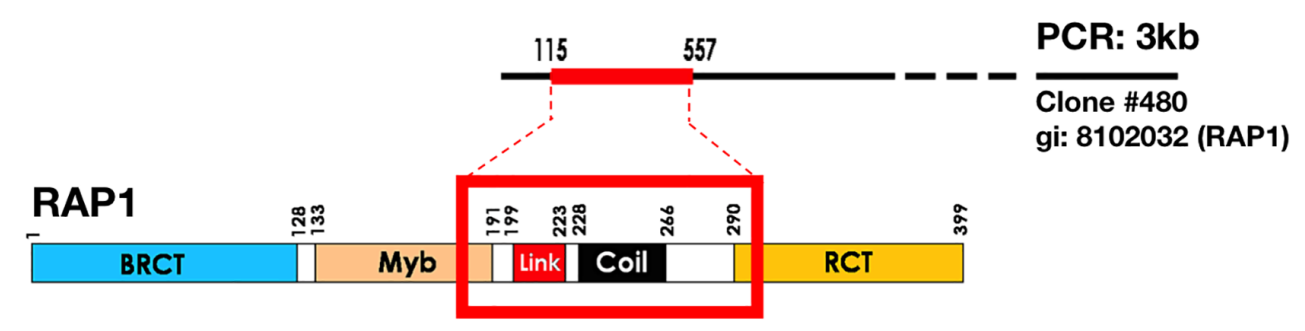

B

\begin{tabular}{|c|c|c|c|c|c|}
\hline RAP1 & BRCT & Myb & Link & Coil & RCT \\
\hline$\triangle B R C T$ & & Myb & Link & Coil & RCT \\
\hline$\triangle R C T$ & BRCT & Myb & Link & Coil & ++ \\
\hline$\Delta R \Delta C$ & BRCT & Myb & Link & & \\
\hline$\Delta \mathrm{Myb}$ & BRCT & & Link & Coil & RCT \\
\hline$\Delta$ Link & BRCT & Myb & & Coil & RCT \\
\hline
\end{tabular}
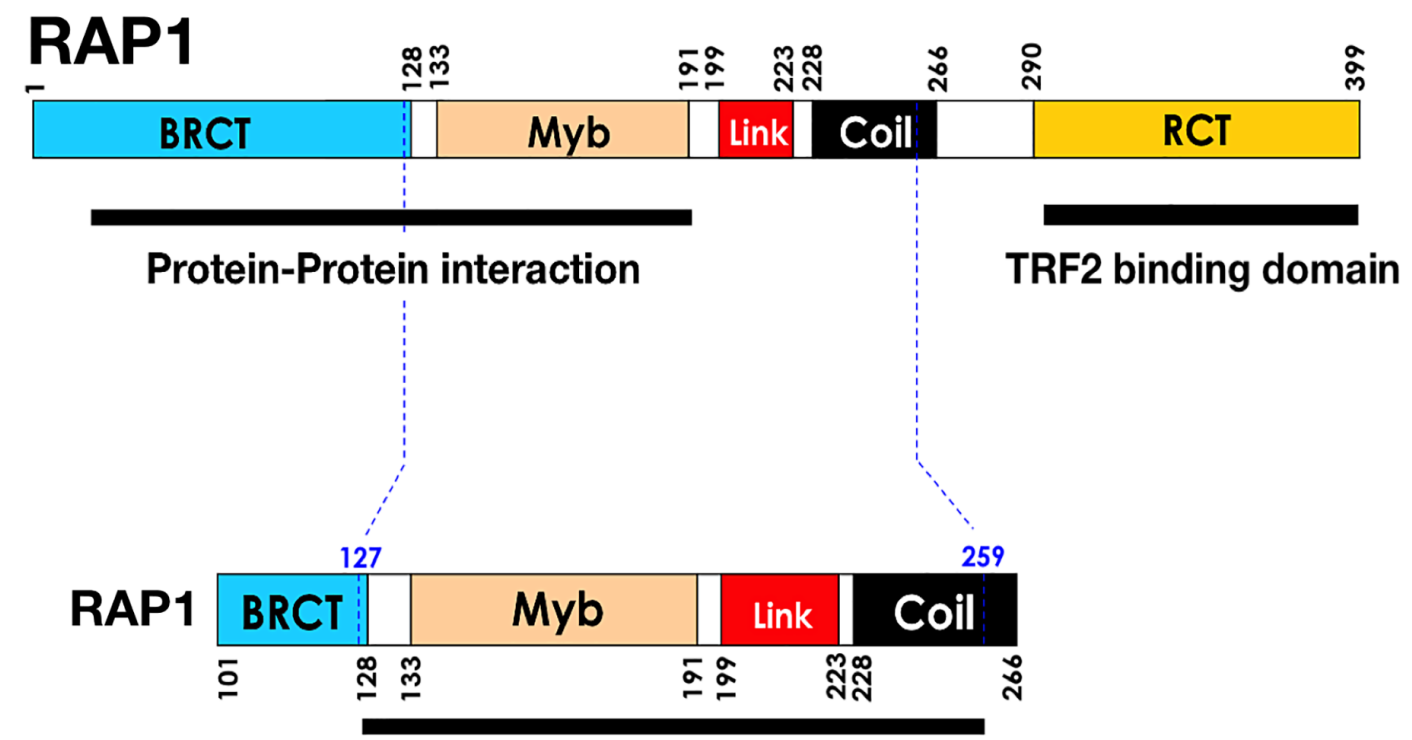

$\mathrm{RAP1} / \mathrm{HRG} \beta_{2}$ interaction region

Figure 1: Y2H mapping of the region of RAP1 that interacts with HRGß2. A. Sequencing analysis of a yeast two-hybrid screen using full-length $\mathrm{HRG} \beta_{2}$ cDNA in the pGBKT7 vector and the human mammary gland Matchmaker cDNA library in the pACT2 vector revealed that RAP1 interacts strongly and in a domain-specific manner with $\mathrm{HRG} \beta_{2}$. B. Yeast was co-transformed with plasmids encoding 1) a fusion protein between the GAL4 activation domain and full-length or deletion hRap1 constructs, and 2) a fusion protein between the pGBKT7 DNA-binding domain and full-length HRG $\beta_{2}$. Representative $\beta$-gal activity (indicated by a blue color) and growth on plates containing selective medium in the yeast two-hybrid assay are presented at the right of the scheme. ++ indicates strong interaction, +/- normal to weak interaction, and - no interaction. BRCT, Myb, Link, Coil, and RCT are RAP1 domains. C. RAP1 interacts with HRG $\beta_{2}$ at amino acids 127 through 259 , specifically at the linker domain. 
This structural architecture has been proposed to function as a protein adaptor, bringing different factors into the telomeric complex [24, 25, 29, 30]; for example, the RCT domain of RAP1 interacts with TRF2 and tethers RAP1 to telomeres. Moreover, deletion analysis of RAP1 has suggested that the BRCT and Myb domains, as well as a novel linker region, may modulate the recruitment of one or more protein factors, which together are required for the execution of negative telomere length control [24, 25, 29, 30]. To further characterize the interaction between RAP1 and HRG $\beta 2$, we generated deletion mutants lacking each of the four functional domains or the linker region, and used these in the $\mathrm{Y} 2 \mathrm{H}$ system. Deletion of the RCT or the BRCT domain did not significantly affect the interaction with HRG $\beta 2$ (Fig. 1B). In contrast, deletion of either the coiled region or the Myb domain evidently reduced the interaction between RAP1 and HRG $\beta 2$. Importantly, no interaction with HRG $\beta 2$ was observed with the RAP1 construct deficient for the linker region (Fig.
1B). Therefore, while the BRCT and Myb domains of RAP1 are not sufficient to bind HRG $\beta 2$, the RAP1 linker domain appears to be essential. These results together with the sequencing data from the $\mathrm{Y} 2 \mathrm{H}$ screen indicate that HRG $\beta 2$ might constitute a novel interactor of the telosome/shelterin complex through its interaction with RAP1 downstream of the BCRT domain, likely between amino acids 127 and 259 (Fig. 1C).

\section{The N-terminal residues of HRGß2 are sufficient to interact with RAP1 in cell nuclei}

To verify the interaction between HRG $\beta 2$ and RAP1 in vivo, we first characterized the nuclear translocation ability of HRG $\beta 2$, which has been demonstrated for other HRG isoforms [21-23]. We transiently transfected MCF-7 BC cells with a mammalian expression plasmid encoding EGFP-tagged full-length HRG $\beta 2$ or the empty pEGFP-C2 vector and examined the distribution of EGFP
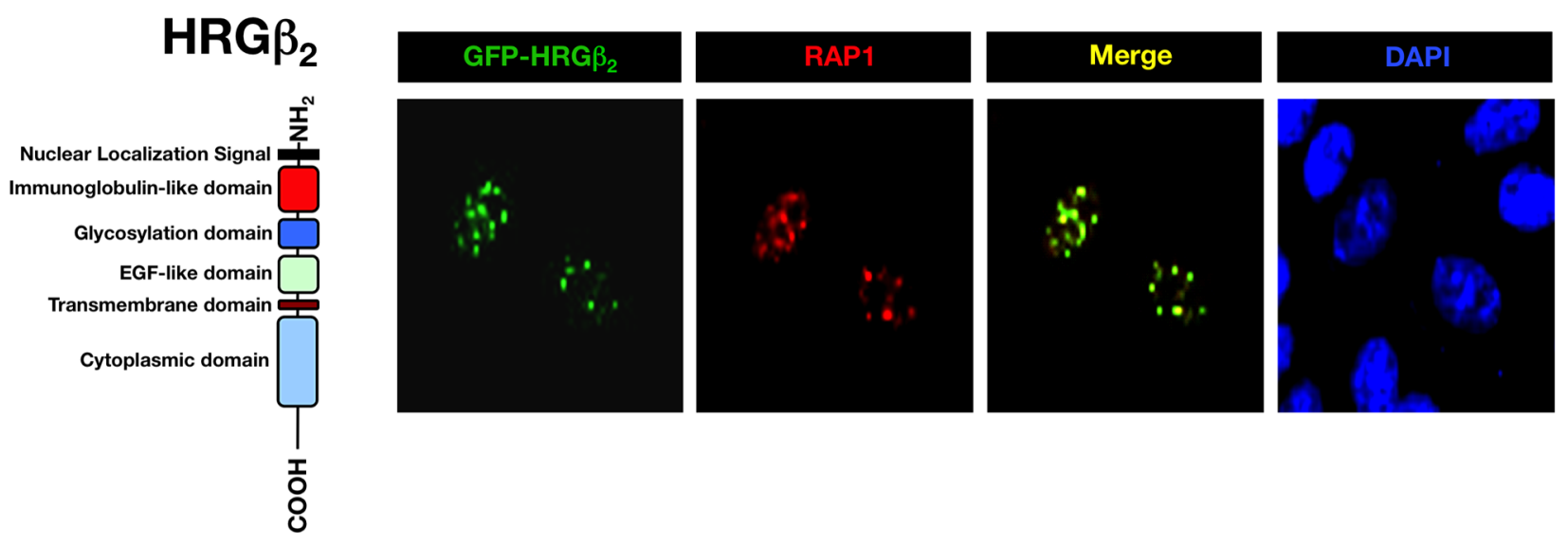

\section{$H R G \beta_{2} \Delta E G F$}
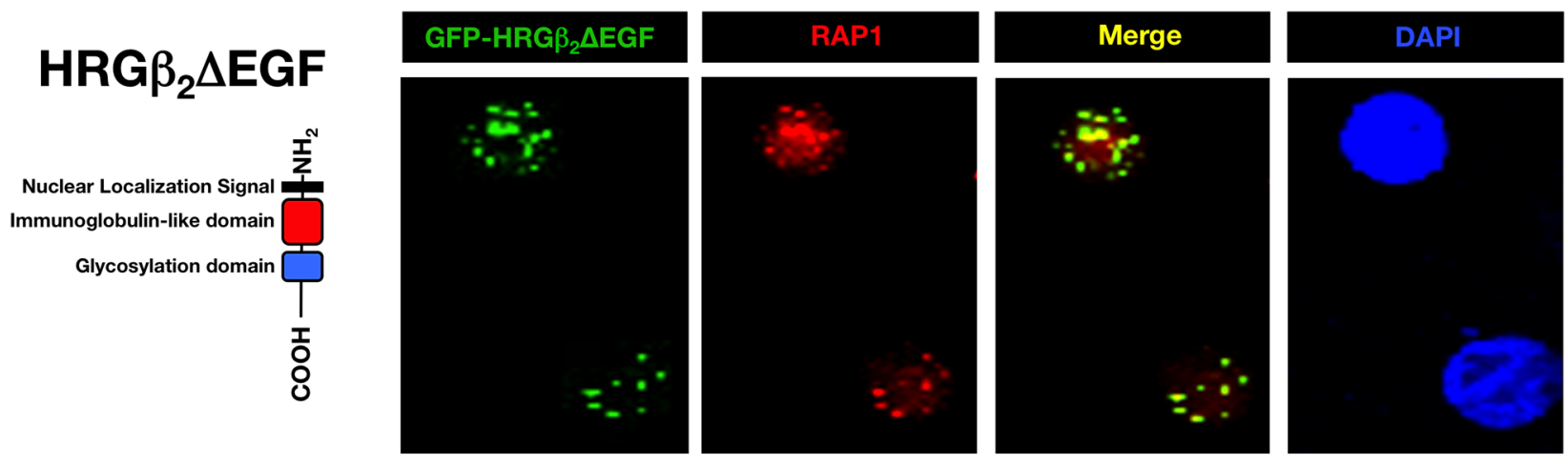

Figure 2: GFP-HRG $\beta 2$ and GFP-HRG $\beta 2 \triangle E$ EF colocalize with RAP1 in MCF-7 breast cancer cells. MCF-7 breast cancer cells were transiently transfected with GFP-HRG $\beta_{2}$ (top, green) or with GFP-HRG $\beta_{2} \Delta$ EGF (bottom, green) and were stained with an anti-RAP1 antibody (red). Colocalization of merged images is indicated in yellow, and DAPI staining (blue) indicates nuclear DNA. The schematic domains of $H R G \beta_{2}$ constructs are shown. Full-length HRG $\beta_{2}$ directs GFP to cytoplasmic membrane, peri-nuclear region, nucleolar-like structures and nuclear speckles. In a significant proportion of cells, the full-length form of HRG $\beta_{2}$ targets GFP to nuclear speckles, as shown in top panels. Merged images revealed co-localization (yellow) of GFP-tagged full-length HRG $\beta_{2}$ with RAP1 in many nuclear speckles. Deleting the EGF-like, the transmembrane and the cytoplasmic domains of HRG $\beta_{2}$ prevented the localization of HRG $\beta_{2}$ to cytoplasmic membrane, peri-nuclear region and nucleolar-like structures. GFP-tagged HRG $\beta_{2} \Delta \mathrm{EGF}$ was targeted to nuclear speckles only in $100 \%$ of transfected cells. Co-staining with anti-RAP1 antibody revealed that the N-terminus residues of HRG $\beta_{2}$, which are sufficient to direct the GFP tag to nuclear speckles, strongly co-localize with RAP1. 
by fluorescence microscopy after $24 \mathrm{~h}$. In contrast to control cells, which had a uniform distribution of GFP throughout the cytoplasm (results not shown), GFPHRG 32 -transfected MCF-7 cells showed localization of the GFP signal to distinct cellular compartments including cytoplasmic membrane, peri-nuclear region, nucleolar-like structures and nuclear speckles (Fig. 2, top). Importantly, immunostaining with an anti-RAP1 antibody demonstrated that GFP-HRG $\beta 2$ concentrated at nuclear speckles, mostly co-localizing with native RAP1 (Fig. 2, top).

To narrow down the sequence necessary for the nuclear import and sub-nuclear localization of HRG $\beta 2$, we constructed several deletion mutants of GFP-HRG $\beta 2$ (unpublished data). We found that $100 \%$ of the cells transfected with an HRG $\beta 2$-derived construct lacking the EGF-like, the transmembrane and the cytoplasmic domains (HRG $\beta 2-\triangle \mathrm{EGF}$ ), exhibited staining at nuclear speckles only (Fig. 2, bottom). Moreover, the speckled distribution pattern of GFP/HRG $\beta 2-\Delta \mathrm{EGF}$ completely co-localized with endogenous RAP1 immunostaining (Fig. 2, bottom). Together, these results confirm that HRG $\beta 2$ appears to interact with RAP1 at cell nuclei and further reveal that the N-terminal residues of HRG $\beta 2$ are sufficient for strong co-localization with RAP1, whereas the C-terminal region of HRG $\beta 2$ is dispensable for RAP1 binding.

\section{HRG $\beta 2$ forms a protein complex with RAP1 in vivo}

To bolster our findings that HRG $\beta 2$ and RAP1 form a protein complex in vivo, we next performed indirect immunofluorescent studies and co-immunoprecipitation assays in MDA-MB-231 and Hs578T BC cells, two metastatic cancer cell models that naturally overexpress HRG $\beta 2$ [16]. Consistent with our results using GFPtagged HRG $\beta 2$ protein in HRG $\beta 2$-negative MCF-7 cells, a
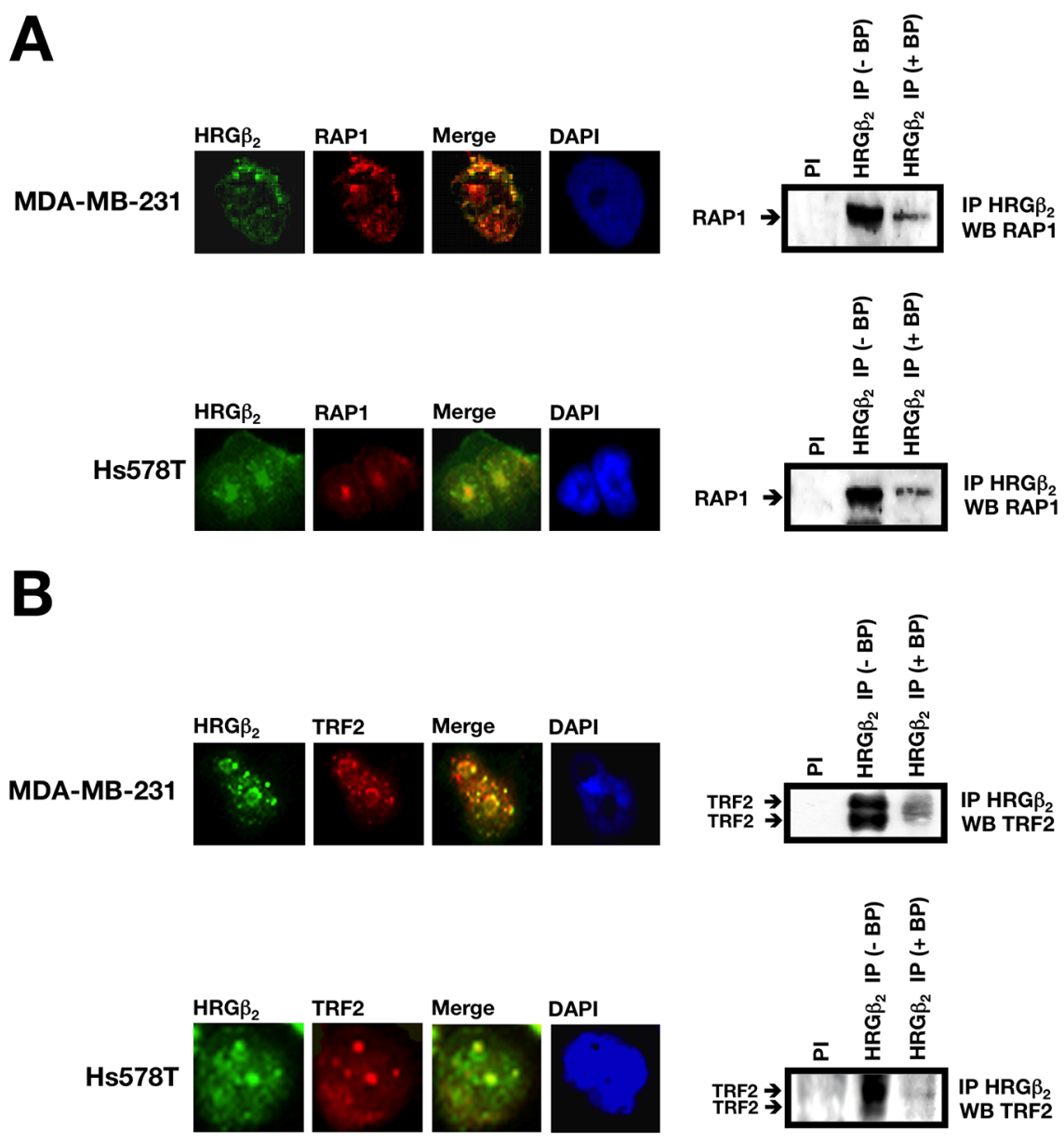

Figure 3: HRG $\beta 2$ co-localizes and co-immunoprecipitates with RAP1 and the RAP1-interacting partner TRF2 in breast cancer cells. Representative immunofluorescent images of MDA-MB-231 and Hs578T cells co-stained for endogenous HRG $\beta_{2}$ (green) and A. RAP1 (red) or B. TRF2 (red) are shown $(n=3)$. Merged images indicate co-localization (yellow). DAPI was used to visualize nuclear DNA (blue). Endogenous $\mathrm{HRG} \beta_{2}$ was immunoprecipitated from MDA-MB-231 or Hs578T nuclear extracts with preimmune serum (PI) or a polyclonal anti-HRG $\beta_{2}$ antibody $\left(\mathrm{HRG} \beta_{2}\right.$ IP) in the absence (-) or presence $(+)$ of a blocking HRG $\beta_{2}$ peptide $(\mathrm{BP})$. Precipitates were separated by SDS-PAGE, transferred to nitrocellulose, and probed with antibodies against A. RAP1 or B. TRF2. One representative immunoblot is shown $(n=3)$. 
prominent sub-nuclear localization of endogenous HRG $\beta 2$ was observed in MDA-MB-231 and Hs578T cells (Fig. $3 \mathrm{~A}$, left panels). Immunostaining with an anti-RAP1 antibody further confirmed that the punctuate distribution pattern of endogenous HRG $\beta 2$ significantly co-localized with endogenous RAP1 (Fig. 3A, left panels). This codistribution of HRG $\beta 2$ and RAP1 occurred throughout the nuclei in essentially all cells, suggesting a lack of dependence on cell cycle status.

Nuclear extracts from MDA-MB-231 and Hs578T cells were immunoprecipitated with protein $\mathrm{A} / \mathrm{G}$ beads coupled to an anti-HRG $\beta 2$ antibody. After elution, the purified proteins were analyzed by immunoblotting using an anti-RAP1 antibody, and compared to crude nuclear extracts or an immunoprecipitate from a non-specific antibody. Western blot analyses of proteins released from the beads revealed that RAP1 co-immunoprecipitated with HRG $\beta 2$ (Fig. 3A, right panels). This association was specific since no RAP1 was recovered with a pre-immune serum; moreover, HRG $\beta 2$-RAP1 co-immunoprecipitation was fully prevented in the presence of a competing peptide directed against the sequence from which the anti-RAP1 antibody was raised (Fig. 3A, right panels).
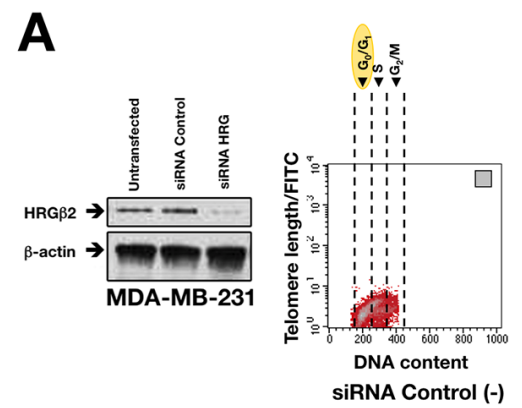

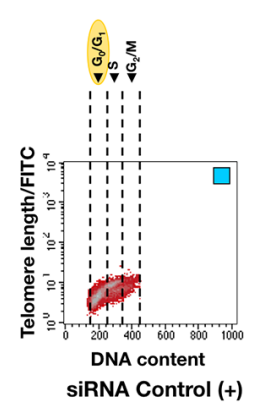

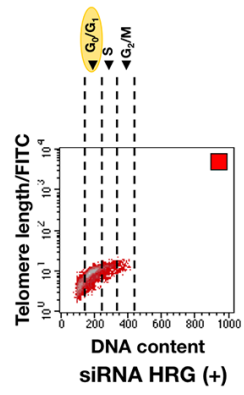

B

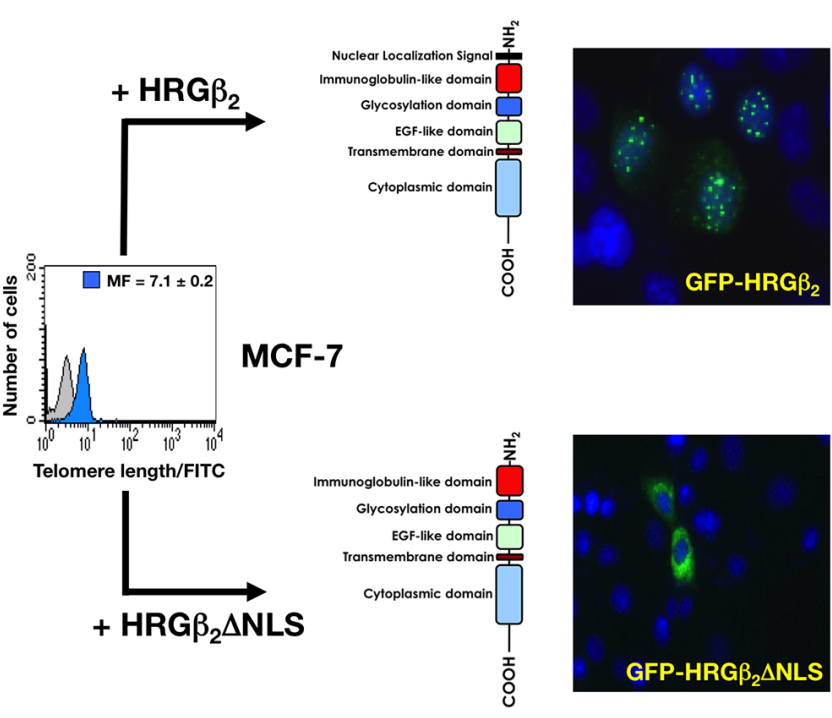

$H R G \beta_{2}$ vs. HRG $\beta_{2} \Delta N L S$

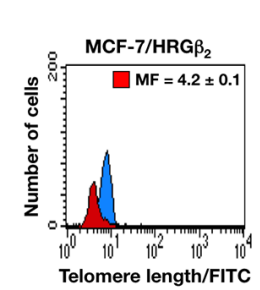

\section{MDA-MB-231}

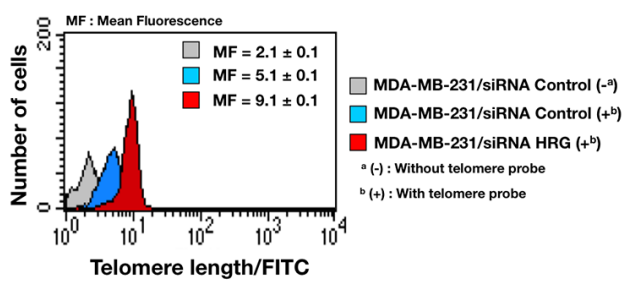

C

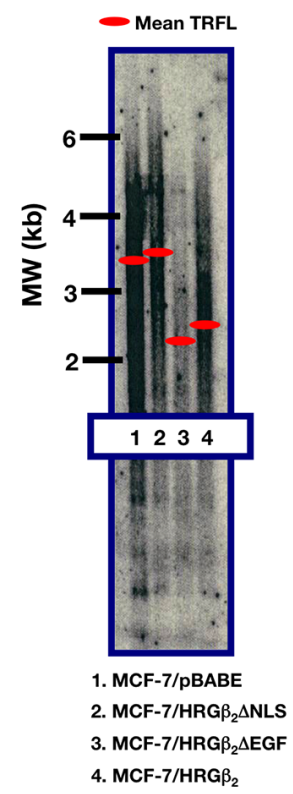

Figure 4: Nuclear HRGß2 negatively regulates telomere length in breast cancer cells. A. Left. Representative immunoblot showing shRNA-mediated knockdown of $\mathrm{HRG}_{2}$ in MDA-MB-231 cells. Right. Flow-FISH analysis of cells in the $\mathrm{G}_{0} / \mathrm{G}_{1}$ phase was performed using a telomere-specific probe as described in the "Materials and methods" section. (-) and (+) indicate Flow-FISH analysis in the absence or presence, respectively, of the telomeric probe. Bivariate cytograms indicate the telomere length in each sub-compartment of the cell cycle. The histograms show the telomere length within the $\mathrm{G}_{0} / \mathrm{G}_{1}$ cell subpopulation, where the cells have only one copy of the genome. Telomere length is expressed in relative fluorescence units (mean $\pm \mathrm{SD}$ ) of four independent experiments. B. MCF-7 cells were transiently transfected with GFP-HRG $\beta_{2}$ or GFP-HRG $\beta_{2} \Delta \mathrm{NLS}$, and telomere length was analyzed by Flow-FISH as described above (n $=3$ ). C. MCF-7 cells were stably transduced with either pBABE retroviral vector alone or pBABE containing cDNA for HRG $\beta_{2} \Delta N L S$ (a structural mutant of $\mathrm{HRG} \beta_{2}$ that lacks the putative NLS), HRG $\beta_{2} \Delta \mathrm{EGF}$ (a structural mutant of HRG $\beta_{2}$ that cannot bind HER3 or HER4 receptors), or for full-length HRG $\beta_{2}$ as specified. Telomere length was assessed by Southern blot analysis of Hinfl/RsaI-digested genomic DNA as described in the "Materials and methods" section. Molecular weight (MW) markers (black bars, in kb) and mean terminal restriction fragment lengths (TRFL; red bars) are indicated. 


\section{HRGß2 interacts with the RAP1 partner TRF2}

Having established a physical interaction between HRG $\beta 2$ and RAP1 in the nuclei of human cancer cells, we next questioned whether HRG $\beta 2$ might also interact with the RAP1 partner TRF2. Similar to previous findings, endogenous TRF2 was found to exhibit a punctuated pattern in the nuclei of MDA-MB-231 and Hs578T cells, as demonstrated by immunofluorescent staining (Fig. 3B, left panels). More importantly, native TRF2 significantly co-localized with endogenous HRG $\beta 2$ (Fig. 3B, left panels). Furthermore, co-immunoprecipitation analysis in MDA-MB-231 and Hs578T cells specifically showed that TRF2 and HRG $\beta 2$ co-precipitate since this interaction was abolished in the presence of an HRG $\beta 2$-derived blocking peptide (Fig. 3B, right panels). This association between HRG $\beta 2$ and RAP1/TRF2-containing protein complexes was not due to tethering by nucleic acids since the addition of ethidium bromide to nuclear extracts during the preclearance step and the immunoprecipitation reaction did not affect the recovery of RAP1 and TRF2 from the HRG 32 immunoprecipitation (data not shown).

\section{Nuclear localization of HRG $\beta 2$ is necessary for HRGß2-driven regulation of telomere length}

Our discovery of the importance of the linker domain of RAP1, a region previously suggested to recruit negative regulators of telomere length [24-27], is consistent with recent findings from our group showing that the proteinaceous link between HRG $\beta 2$, TRF2, and RAP1 might explain HRG $\beta 2$ 's ability to negatively regulate telomere length [31]. We therefore investigated whether the nuclear co-localization of HRG $\beta 2$ with the RAP1/TRF2 complex was required for HRG $\beta 2$-driven regulation of telomere length. We first needed to confirm that HRG $\beta 2$ is a novel regulator of telomere length [31]. Using fluorescent in situ hybridization (FISH) with labeled peptide nucleic acid (PNA) probes specific for telomere repeats, in combination with fluorescence measurements by flow cytometry (flow FISH), we verified that transient shRNA-driven knockdown of HRG $\beta 2$ expression was sufficient to rapidly promote significant lengthening of telomeres in the highlyaggressive, HRG $\beta 2$-overexpressing MDA-MB-231 BC cell line (Fig. 4A). We then evaluated whether the minimal structural requirements for HRG $\beta 2$ nuclear translocation determined its ability to regulate telomere length. We identified a putative nuclear localization signal (NLS) in the N-terminus (extracellular domain) of HRG 32 , between amino acids 4 and 16 . To test the functionality of this region, we deleted the first 33 amino acids of the HRG $\beta 2$ cDNA containing this putative NLS and analysed HRG $\beta 2$ nuclear translocation. Indirect immunofluorescence of MCF-7 BC cells transiently transfected with the GFP/
HRG $\beta 2-\Delta$ NLS fusion expression plasmid revealed that the deletion of the NLS domain completely prevented its transport to the nucleus. Accordingly, a striking perinuclear accumulation of GFP/HRG $\beta 2-\triangle N L S$ was clearly seen in most cases in transfected cells, in comparison with the prominent nuclear speckles observed with transfected full-length HRG $\beta 2$ protein (Fig. 4B). Importantly, whereas MCF-7 cells transiently transduced to express high levels of full-length HRG $\beta 2$ exhibited telomere shortening as revealed by a significantly lower telomeric fluorescence intensity on Flow-FISH analyses, we failed to observe significant changes in the telomere length of MCF-7 cells transiently transduced to express high levels of HRG $\beta 2$ lacking the NLS sequence (Fig. 4B). To complement this finding, we analyzed telomere length by pulse-field gel analysis of digested genomic DNA followed by Southern blot hybridization using a telomere-specific probe. In MCF-7 cells stably overexpressing either full length HRG $\beta 2$, HRG $\beta 2-\Delta$ NLS or HRG $\beta 2-\Delta$ EGF constructs, we found that the nuclear localization of HRG $\beta 2$ was necessary to promote telomere shortening, and the $\mathrm{N}$-terminal (extracellular) amino acids of HRG $\beta 2$ are sufficient to promote this effect (Fig. 4C).

\section{DISCUSSION}

A growing number of growth factors such as FGF, amphiregulin and PDGF have been identified in the nucleus [32-36]. The biological implications of such localizations, however, are not well understood and remain contentious. We show for the first time that HRG $\beta 2$ unexpectedly functions as an interactor of the telosome/shelterin complex in the nucleus by virtue of its direct interaction with RAP1, a negative regulator of telomere length that associates with telomeres primarily through its interaction with the telomere-binding protein TRF2. Specifically, the region of RAP1 that interacts with HRG $\beta 2$ necessarily involves its linker region. Earlier studies showed that a RAP1 mutant lacking this region was incapable of extending telomeres, and results from deletion analyses suggested that the linker region could modulate the recruitment of putative negative regulators of telomere length $[24,25,29,30]$. Consistent with these findings, we found that changes in HRG $\beta 2$ expression and sub-cellular compartmentalization were concomitant with rapid and detectable alterations in telomere length, thus supporting the notion that HRG $\beta 2$ acts as a previously unrecognized negative regulator of telomere length and is recruited by the linker domain of RAP1.

How might HRG $\beta 2$ regulate telomere length? It has been described that expression of a RAP1 mutant lacking the linker region reduced the number of TRF2 foci in cells. This result suggests that while the RAP1- $\Delta$ linker construct was still able to interact with TRF2, it may disrupt the interaction of TRF2 with the telomere and, consequently, lead to a reduction in average telomere length $[29,30]$. 
Alternatively, the linker domain might be also involved in the recruitment of yet unidentified negative regulators of telomere length. Because our findings reveal that HRG $\beta 2$ is not a core component but rather an accessory factor of the telosome/shelterin complex, the ability of HRG $\beta 2$ to simultaneously co-interact with RAP1 and TRF2 may reconcile these two hypotheses. Suppression of HRG $\beta 2$ expression or prevention of its efficient nuclear translocation might uncouple the RAP1/TRF2 complex from sequestering the telomere ends and allow access of telomerase to its substrate. Conversely, HRG $\beta 2$ overexpression or nuclear accumulation of HRG $\beta 2$ might promote the stabilization of the RAP1/TRF2 complex at the chromosome ends, thus leading to telomere shortening.
In line with this concept, we found that forced expression of HRG $\beta 2$ in HRG $\beta 2$-negative $B C$ epithelial cells is sufficient to induce the up-regulation and the stabilization of RAP1/TRF2 complexes while coincidentally promoting telomere shortening. Knockdown of HRG $\beta 2$, however, decreases the abundance of TRF2 and RAP1 proteins and reduces their telomeric content while concomitantly inducing telomere lengthening [31]. These RAP1/TRF2related telomere-regulating actions of $\mathrm{HRG} \beta 2$ recapitulate the features found by deleting the linker region of RAP1 [24]. Since most if not all TRF2 is in a complex with RAP1, it is reasonable to suggest that HRG $\beta 2$ might function as a direct interacting partner for stable binding between RAP1 and TRF2. In this scenario, HRG $\beta 2$
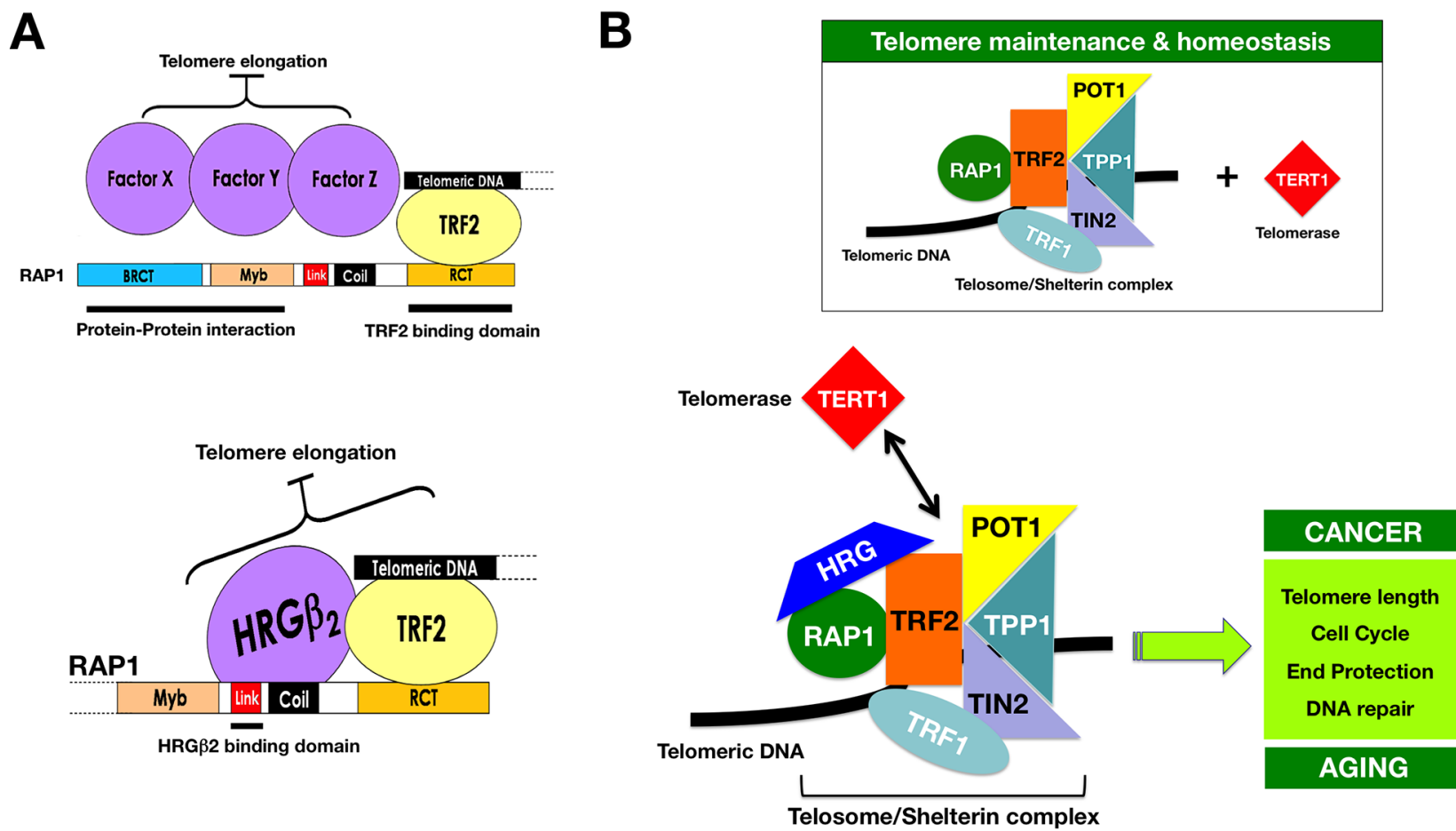

Figure 5: HRGß2: A novel interactor of the telosome/shelterin complex. A. Data reported by Li \& Lange [30] and O'Connor et al. [24] originally suggested that RAP1 is a negative regulator of telomere length and that the BRCT, linker and/or Myb domains were required for this regulatory function. It was proposed that these RAP1 domains should interact with a factor(s), i.e., either three different proteins, $X, Y$, and $Z$, or different domains of the same protein(s), which will be required for negative regulation of telomere length. Our current mapping of the interacting regions between RAP1 and $\mathrm{HRG} \beta_{2}$, together with the sequencing data from the Y2H screen, reveal that $\mathrm{HRG} \beta_{2}$ is a novel interactor of the telosome/shelterin complex through its interaction downstream of the BRCT domain of RAP1, likely between amino acids 127 and 259 . HRG $\beta_{2}$ should be viewed as one of the unknown negative regulators of telomere length recruited by the linker domain of RAP1 that, in addition, simultaneously interacts with the RAP1 partner TRF2. B. The delineation of the 6 telomeric proteins (TRF1, TRF2, TIN2, RAP1, TPP1, and POT1) and their associated partners has provided the basis for constructing an interaction map of telomere regulators in mammalian cells, the so-called telomere interactome [6-8], which represents the molecular machinery that controls mammalian telomeres and enables the integration of the various signaling pathways that regulate telomeres with other cellular interactomes. At the core of the telomere interactome is the telosome/shelterin complex, which can recruit a multitude of factors through various telosome subunits (e.g., RAP1) and mostly through protein hubs, which mediate multiple interactions with other proteins in the telomere interactome consistent with their key roles in telomere control (e.g., TRF2). Because TRF2 directly binds telomere DNA and recruits different proteins that are involved not only in cell cycle, DNA repair and recombination but also in end protection (e.g., RAP1) $[6-8,55]$, the ability of $H R G \beta_{2}$ to interact with RAP1 and TRF2 strongly suggest that HRG $\beta_{2}$ may significantly alter the protein-protein interaction within the telomere interactome to regulate telomere function and dynamics in normal development or in diseased cells, such as cancer and aging cells. Whether the RAP1-HRG $\beta_{2}$-TRF2 interaction actually determines whether the telomerase complex can be recruited or displaced from the core of the telosome/shelterin complex and/or whether TRF2 can efficiently remodel the telomere end into t-loop structures [55], which sequester and protect the ends of chromosomes, remains to be determined. 
could function to modulate correct telomere tethering of this telosome/shelterin complex subunit and, ultimately, regulate telomere homeostasis maintenance (Fig. 5A).

Our current findings revealing the telomere-related "intracrine" functioning of HRG $\beta 2$ supports the concept that, in a counterintuitive manner, secreted growth factors such as the HRG family, can promote highly specific actions in defined cellular compartments. This discovery adds even more complexity to the "import(ance) of growth factors in(to) the nucleus" [32-36] and may have significant implications in our molecular understanding of the natural history of age-related pathologies including cancer. Indeed, our current findings provide molecular support to our "telomere-dependent" hypothesis, integrating epithelial BC, aging stroma and cellular senescence, by considering an unforeseen telosomic activity of HRG [37-40]. Earlier studies from our laboratory described how senescent human fibroblasts significantly stimulated hyperproliferation and progression of pre-neoplastic breast epithelial lesions and accelerated the tumorigenic capacity of neoplastic breast epithelial cells [41]. The BC-promoting activity of senescent cells was likely due to the secretory phenotype of senescent fibroblasts, which is characterized by changes in the expression of cell type-specific genes [39, 42, 43]. While acknowledging that the critical factor(s) produced by aging -senescent- stroma for the stimulation of precancerous and cancerous breast epithelial lesions remains an unanswered question, it is relevant to note that HRG is one of the major growth factors secreted by senescent fibroblasts [42, 44]. Beyond the well-characterized autocrine/paracrine activating actions of $\mathrm{HRG}$ on the erbB network-driven signaling, its intracrine regulation of telomere-dependent genome stability may provide a key rate-limiting step in breast carcinogenesis and metastatic progression. Short telomeres have been shown to generate chromosome instability, which in turn may lead to an increased risk of several cancers including breast carcinoma [45-47]. As an illustration, we now know that transition through telomere crisis and immortalization is a crucial event in $\mathrm{BC}$ that occurs during progression from typical ductal hyperplasia to pre-invasive ductal carcinoma in situ (DCIS), as well as in focal areas of histologicallynormal epithelium from which breast carcinoma is thought to arise [48, 49]. In this scenario, an HRG-induced shortening of telomeres in breast epithelial cells, as an additional driver of chromosome destabilization in the early stages of breast tumorigenesis, may molecularly link the tumorigenic role of HRG-overproducing senescent cells at sites of age-related pathologies such as BC. Indeed, a reduced telomeric DNA content correlates with genomic instability and metastasis in invasive breast carcinomas $[50,51]$. Remarkably, pro-metastatic HRG proteins have recently been found to significantly accumulate not only in cell nuclei of invasive breast carcinomas but also in DCIS, whereas no nuclear HRG is found in normal tissues
$[22,52]$. Therefore, it is reasonable to suggest that some cancer promoting actions of the aging stroma can rely, at least in part, on its ability to secrete enormous amounts of HRG which, in turn, will trigger and maintain telomere shortening in the breast epithelial compartment in a RAP1/ TRF2-dependent manner.

The elucidation of the interaction and function of the core proteins TRF1, TRF2, RAP1, TIN2, POT1, and TPP1 within the telosome/shelterin complex has allowed a better understanding of the molecular intricacies that ultimately regulate telomere end-capping and length control. It is now known that the telosome/shelterin complex forms the basic platform on which layers of telomere signaling networks can be assembled onto the socalled telomere interactome $[6,7]$ for the proper protection and maintenance of mammalian telomeres. Considering the ever-growing list of proteins that integrate the complex and labyrinthine network of the telomere interactome, one can wonder "how there is even room" for new regulators at chromosome ends [53, 54] (Fig. 5B). Our study refines the current appreciation of the telomere interactome by incorporating the nuclear version of the growth factor HRG as a constituent of the various telomere-signaling pathways and telomere-associated molecular machinery that regulate mammalian telomeres. Future studies are warranted to explore in detail the function of HRG at telomeres and to dissect the mechanisms by which HRG communicates with the telosome/shelterin complex core to coordinate different cellular signaling pathways for telomere maintenance including cell cycle, telomere length, end protection or DNA repair in cancer and aging. Our current findings reveal that a new, but likely not the last, unforeseen player has been added to the "telosome/ shelterin town".

\section{MATERIALS AND METHODS}

\section{Cloning of HRGß2}

Poly (A) RNA was extracted from $\mathrm{HRG}_{2}{ }_{2}$ overexpressing MDA-MB-231 BC cells using the Oligotex Direct mRNA Kit (Qiagen). Three $\mu \mathrm{g}$ of poly (A) RNA was reverse transcribed and amplified using the Gene Amp RNA PCR Kit (Applied Biosystems). To obtain the entire ORF of $\mathrm{HRG} \beta_{2}$, the digested PCR product was cloned into the pRcCMV plasmid (Met1 to Ser422) using the BSU361 and $X b a \mathrm{I}$ sites. The region encoding the $\mathrm{C}$-terminal domain of $\mathrm{HRG}_{2}$ (Phe401 to Val636) was amplified using primers 5'- TCAGGCATGCCAGAGAAACC-3' and 5'-ATTATACAGCAATAGGGTCTTGGTT-3'. 


\section{Yeast two-hybrid assay}

The yeast two-hybrid assay was performed according to the Matchmaker Gal4 two-hybrid system 3 manual (CLONTECHniques). The yeast strain AH109 containing $A D E 2, H I S 3$, lacZ, and MEL1 reporter genes, each of which uses a distinct GAL4-responsive promoter, was used in the assay. These distinct promoter elements automatically eliminate three major categories of false positives: those caused by proteins that interact upstream of the reporter construct binding site, those that interact directly with the sequences flanking the GAL4 binding site, and those that interact with transcription factors bound to specific TATA boxes. The entire $\mathrm{HRG} \beta_{2} \mathrm{ORF}$ was sub-cloned in frame into the DNA-Binding Domain (BD) vector $\mathrm{pGBKT} 7$. The $\mathrm{pGBKT} 7-\mathrm{HRG} \beta_{2}$ bait vector and the human mammary gland Matchmaker cDNA library in the pACT2 vector were co-transformed into strain AH109 and grown on minimal synthetic medium lacking Ade, His, Leu and Trp to test potential interactors. The HRG $\beta_{2}$ bait did not have any intrinsic activity of transcriptional activation for the reporters (data not shown). The $\mathrm{X}-\alpha-\mathrm{Gal}$ (5-Bromo-4-chloro-3-indolyl- $\alpha$-D-galactopyranoside)

indicator was included to screen transformants.

Approximately $1 \times 10^{6}$ independent transformants were pooled and re-plated on selection media (Ade-, His, Leu and $\mathrm{Trp}^{-}$) containing $2 \%$ galactose (Gal) to induce the expression of cDNAs. In total, 35 transformants showed Gal-dependence in the selction medium. Plasmids from these transformants were extracted by yeast mini-prep and the cDNAs were amplified in the PCR with primers derived from the pJG4-5 vector, followed by sequence determination. To eliminate false positive, we performed separation and isolation of yeast plasmids followed by propagation in bacteria. This approach revealed that: 1 clone was not in frame with GAL4, 6 clones included 3' untranslated regions (UTRs), while 24 clones were found to be artifactual positive yeast clones. The two truly positive clones including ORFs for known genes were found to encode for the telomere-related proteins SC-35 and RAP1 (see text).

Mapping of the interacting domains of RAP1 and HRG $\beta 2$. AH109 cells were co-transformed with plasmids encoding a fusion protein between the GAL4 activation domain (AD) and full-length RAP1 (pACT2-hRap1, a gift from Dr Titia de Lange), or RAP1 deleted constructs and a plasmid encoding a fusion protein between fulllength $\mathrm{HRG} \beta_{2}$ and the DNA-BD included in pGBKT7, using a small-scale LiAc/ssDNA/PEG transformation protocol. RAP1 truncations were generated by PCR as described (24): hRap1 (full-length, amino acids 1-198), $\Delta$ Myb (amino acids 1-132 and 192-399), $\Delta$ Link (amino acids 1-198 and 224-399), $\Delta \mathrm{RCT}$ (amino acids 1-290, with an $\mathrm{N}$-terminal nuclear localization signal PRRK), $\Delta \mathrm{R} \Delta \mathrm{C}$ ( $\Delta \mathrm{RCT} / \Delta$ Coil-Coil, amino acids 1-227, with an N-terminal nuclear localization signal PRRK), and $\triangle \mathrm{BRCT}$ (amino acids 129-399). Transformants were plated onto appropriate minimum synthetic dropout media and then tested for $\beta$-galactosidase activity.

\section{Generation and visualization of GFP-HRGß2}

A full length $H R G \beta_{2}$ enhanced green fluorescent protein (EGFP) fusion construct was engineered by removing the HRG $\beta_{2}$ insert from $\mathrm{pGBKT} 7 / \mathrm{HRG} \beta_{2}$ with $E c o$ RI and BamHI and cloning into the equivalent sites of pEGFP-C2. Structural deletion mutants of $\mathrm{HRG}_{2}$ were generated by PCR and cloned into pEGFP-C2 or pEGFP-N2 vectors digested with EcoRI and BamHI.

MCF-7 cells were used for transient expression analysis of GFP-HRG $\beta_{2}$ constructs. Cells were grown on glass coverslips to $60 \%-80 \%$ confluence and were transfected for 6 hours with $1 \mu \mathrm{g}$ plasmid DNA using FuGENE transfection reagent (Roche, Indianapolis, IN). Transfected cells were seeded on glass coverslips in six-well plates and incubated for 24 hours. Cells were fixed/permeabilized with $0.2 \%$ Triton X-100/2\% paraformaldehyde and permeabilized again in $100 \%$ methanol for 10 minutes at $-20{ }^{\circ} \mathrm{C}$. Coverslips were blocked for 30 minutes at $37^{\circ} \mathrm{C}$ in $5 \%$ BSA in phosphatebuffered saline (PBS), incubated with a RAP1-specific antibody (1:200 dilution of IMG-272, Imgenex, San Diego, CA), washed, and incubated with Texas Redconjugated anti-mouse IgG. Coverslips were mounted with 4,6-diamidino-2-phenylindole (DAPI) onto microscope slides. Cells were observed and analyzed using a Zeiss Axioskop microscope equipped for epifluorescence.

\section{Fluorescence microscopy}

MDA-MB-231 and Hs578T cells were grown on glass coverslips to $60 \%-80 \%$ confluence and fixed/ permeabilized/blocked as described above. Cells were then stained with $\mathrm{HRG} \beta_{2}-$, RAP1- and/or TRF2-specific antibodies (1:100 dilution of the anti-HRG $\beta_{2}$ C20 antibody -sc-348-; Santa Cruz Biotech. Santa Cruz, CA and 1:200 of anti-RAP1 or anti-TRF2 IMG-124 antibody, Imgenex, San Diego, CA) and then incubated with Texas Redconjugated anti-mouse IgG for hRap1 and TRF2 (red) and FITC-conjugated anti-rabbit IgG antibody for $\mathrm{HRG} \beta_{2}$ (green).

\section{Immunoprecipitation and western blotting}

For co-immunoprecipitation (IP) analysis of $\mathrm{HRG} \beta_{2}$ and RAP1/TRF2, MDA-MB-231 and Hs578T cultures were expanded on $15-\mathrm{cm}$ plates. At confluence, cells were trypsinized, collected in a10X pellet volume of PBS and lysed using the EZ Prep Nuclei Isolation Kit (SigmaChemicals, St. Louis, MO). The purified nuclei were 
resuspended in a $3 \mathrm{X}$ pellet volume in low salt nuclear extraction buffer [20 mmol/L Tris, $\mathrm{pH} \mathrm{7.3,} 20 \mathrm{mmol} / \mathrm{L}$ $\mathrm{KCl}, 25 \%$ glycerol, $1.5 \mathrm{mmol} / \mathrm{L} \mathrm{MgCl}_{2}, 0.2 \mathrm{mmol} / \mathrm{L}$ EDTA, 1X phenylmethylsufonyl fluoride, and a complete protease inhibitor mixture tablet]. An equal volume of high salt nuclear extraction buffer $(1.2 \mathrm{M} \mathrm{KCl}, 20 \mathrm{mmol} / \mathrm{L}$ Tris, $\mathrm{pH} 7.3,25 \%$ glycerol, $1.5 \mathrm{mmol} / \mathrm{L} \mathrm{MgCl}_{2}, 0.2$ $\mathrm{mmol} / \mathrm{L}$ EDTA) was added and the nuclear extract was kept on ice for $30 \mathrm{~min}$ with occasional vortexing. The sample was then centrifuged at 14,000 rpm for 15 minutes and the supernatant was diluted with an equal volume of water. One mg of nuclear protein was pre-cleared using $1.25 \mu \mathrm{g}$ of rabbit $\mathrm{IgG}$ and $20 \mu \mathrm{L}$ of $\mathrm{A} / \mathrm{G}$ beads for $30 \mathrm{~min}$ at $4{ }^{\circ} \mathrm{C}$ (pre-immune-PI-). The supernatant was incubated for 2 hours with $1 \mu \mathrm{g}$ of C-20 anti-HRG $\beta_{2}$ antibody (sc348; Santa Cruz Biotech.) in the absence or presence of an $\mathrm{HRG} \beta_{2}$ blocking peptide. Twenty $\mu \mathrm{L}$ of $\mathrm{A} / \mathrm{G}$ beads were added and the mixture was incubated overnight at $4{ }^{\circ} \mathrm{C}$. Ethidium bromide or RNase A was added to the nuclear extracts (both at a final concentration of $100 \mu \mathrm{g} /$ $\mathrm{ml}$ ) during preclearance and throughout the IP procedure. Immunocomplexes were washed several times with NETN buffer [20 mmol/L Tris, pH 8.0, $100 \mathrm{mmol} / \mathrm{L} \mathrm{NaCl,} \mathrm{0.5 \%}$ Nonidet P-40, $1 \mathrm{mmol} / \mathrm{L}$ EDTA), boiled in SDS loading buffer, separated on $10 \%$ SDS-PAGE gels and transferred to nitrocellulose membranes. Nonspecific binding was minimized by blocking the membranes for $1 \mathrm{hr}$ at room temperature (RT) with TBS-T [25 mmol/L Tris-HCl, 150 $\mathrm{mmol} / \mathrm{L} \mathrm{NaCl}, \mathrm{pH} 7.5$, and $0.05 \%$ Tween 20 ] containing $5 \%(w / v)$ nonfat dry milk. The treated filters were washed in TBS-T and then incubated with anti-hRapl and anti-TRF2 primary antibodies for $2 \mathrm{hr}$ at RT in TBS-T containing $1 \%(w / v)$ nonfat dry milk. After a subsequent wash in TBS-T, horseradish peroxidase-conjugated secondary antibodies (Jackson Immunoresearch Labs, West Grove, PA) in TBS-T were added for $1 \mathrm{hr}$, and immunoreactive bands were detected by enhanced chemiluminescence reagent (Pierce, Rockford, IL).

\section{Generation of MCF-7 cells overexpressing full-

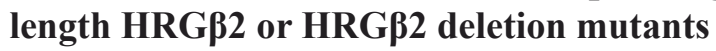

The PCR products generated using the HRG $\beta_{2}$ cDNA accession number 183996 (full length $\mathrm{HRG} \beta_{2}$ ) or the structural deletion mutants $\left(\mathrm{HRG} \beta_{2}-\Delta \mathrm{NLS}\right.$ and HRG $\left.\beta_{2}-\triangle E G F\right)$ were cloned into the retroviral expression vector pBABE-Puro using BamHI and EcoRI restriction sites. Retroviral constructs were transfected into a high efficiency transient amphotropic packaging system (TSA54 cell line) with FuGENE reagent. Retroviruscontaining medium collected after $48 \mathrm{~h}$ was used to infect MCF-7 cells for $24 \mathrm{~h}$ in the presence of Polybrene (Sigma-Chemicals). Infected MCF-7 cells were grown for an additional 24 hours in standard medium and stable cell lines (MCF-7/pBABE, MCF-7/HRG $\beta_{2}, \mathrm{MCF}-7 / \mathrm{HRG}_{2}-$ $\triangle \mathrm{NLS}$ and $\mathrm{MCF}-7 / \mathrm{HRG}_{2}-\Delta \mathrm{EGF}$ ) were selected and expanded in the presence of $2.5 \mu \mathrm{g} / \mathrm{mL}$ puromycin for two weeks. Expression levels of HRG $\beta_{2}, H R G \beta_{2}-\Delta N L S$ and HRG $\beta_{2}-\Delta$ EGF were assessed by RT-PCR using the Gene Amp Kit (Promega Corporation). Alternatively, cells were transiently transduced with replication-incompetent amphotropic retroviruses containing either a full-length HRG $\beta_{2}$ cDNA construct or a HRG $\beta_{2}-\Delta$ NLS deletion cDNA construct cloned in the pLXSN (LTR-gene X-simian virus 40-Neo) retroviral expression vector (Clontech) in the presence of $4 \mu \mathrm{g} / \mathrm{mL}$ polybrene. Viruses were added at appropriate dilutions, and the cells incubated for $48 \mathrm{~h}$ to allow expression of the HRG $\beta_{2}$ or $H R G \beta_{2}-\Delta$ NLS proteins from the integrated $\mathrm{pLXSN}$ vector.

\section{HRG gene silencing by small interfering RNAs}

An siRNA duplex used for silencing the human HRG was purchased from Santa Cruz Biotech. Transfections were performed as described in the technical bulletin.

\section{Telomere analysis by fluorescence in situ hybridization and flow cytometry}

Analysis of telomeres by flow cytometry using FISH was performed with a kit from DakoCytomation Denmark A/S (Glostrup, Denmark), Code No. K5327. Briefly, $\sim 2 \times 10^{6}$ cells were resuspended in $300 \mu \mathrm{L}$ of hybridization buffer $(70 \%$ deionized formamide, 10 $\mathrm{mmol} / \mathrm{L}$ Tris, $\mathrm{pH} 7.0,10 \%$ fetal bovine serum, FBS) in the absence or presence of $0.3 \mu \mathrm{g} / \mathrm{mL}$ of the telomere-specific fluorescein isothiocyanate-conjugated probe (fluorescein isothiocyanate-O-CCCATAACTAAACAC-NH ${ }_{2}$ ). DNA from samples was heat-denatured for 10 minutes at $82^{\circ} \mathrm{C}$, followed by hybridization for 2 hours at RT. Cells were washed in wash buffer containing 70\% deionized formamide, $10 \mathrm{mmol} / \mathrm{L}$ Tris, $\mathrm{pH} 7.0,10 \% \mathrm{FBS}$ and $0.1 \%$ Tween 20. After incubation for 1 hour at RT, cells were washed and resuspended in PBS, $10 \%$ FBS, $10 \mu \mathrm{g} / \mathrm{mL}$ RNase A (Roche Molecular Diagnostics), and propidium iodide, incubated for 1 hour at RT, washed, and analyzed in a FACScalibur flow cytometer (Becton Dickinson). Cell Quest software (Becton Dickinson) was used for data acquisition and analysis. The telomere fluorescence signal was defined as the mean fluorescence signal in $\mathrm{G}_{0} / \mathrm{G}_{1}$ cells after subtraction of the background fluorescence signal (FISH procedure without probe). The flow cytometer was calibrated every day using fluorescein isothiocyanatelabeled fluorescence Sphero microparticles (Pharmingen). The resulting calibration curve was used for correction of experimental fluorescence values in each experiment. Green fluorescence was measured in a linear scale, and results were expressed in molecular equivalents of soluble fluorochrome units (kMESF). 


\section{Southern blotting analysis of Terminal Restriction Fragment (TRF) length}

Cells from a sub-confluent 100-mm diameter culture dish were harvested by trypsinization, washed in cold PBS, collected by centrifugation for $5 \mathrm{~min}$ at 1,500 rpm, and counted using the Coulter counter. Cell pellets were frozen at $-80^{\circ} \mathrm{C}$ until utilization. Genomic DNA was isolated from cell pellets (approximately $5 \times 10^{6}$ cells for each cell line) using a DNA extraction kit (Qiagen, Santa Clarita, CA) with inclusion of an RNase A digestion step, and quantitated with a spectrophotometer. Protein-free DNA was cleaved with Hinfl and RsaI restriction enzymes (Gibco/BRL), extracted once with phenol/chloroform/ isoamyl alcohol, ethanol precipitated, and resuspended in Tris-EDTA to generate the TRF. A portion of DNA was subjected to electrophoresis in a $0.5 \%$ agarose gel in $1 \mathrm{X}$ Tris-Borate EDTA (TBE) buffer at $2 \mathrm{~V} \mathrm{~cm}^{-1}$ for 17 hours. The gel was dried at $60^{\circ} \mathrm{C}$ for 2 hours, denatured for 30 60 minutes in $0.5 \mathrm{~mol} / \mathrm{L} \mathrm{NaOH}$ and $1.5 \mathrm{~mol} / \mathrm{L} \mathrm{NaCl}$, and neutralized for 30-60 minutes in $1 \mathrm{~mol} / \mathrm{L}$ Tris- $\mathrm{HCl}, \mathrm{pH}$ 8.0 and $1.5 \mathrm{~mol} / \mathrm{L} \mathrm{NaCl}$. The dried gel was then subjected to in-gel hybridization with a $\left[\gamma_{-}{ }^{32} \mathrm{P}\right]-\mathrm{ATP} 5^{\prime}$ end-labeled oligonucleotide telomeric probe $\left[\gamma^{-32} \mathrm{P}-(\mathrm{TTAGGG})_{3}\right]$. The autoradiography signal was digitized using a Phosphoimager (Amersham Biosciences) and ImageQuaNT software (Molecular Dynamics). The mean size of the TRF was estimated using the formula $\mathrm{L}=\mathrm{E}\left(\mathrm{OD}_{\mathrm{i}} \cdot \mathrm{L}_{\mathrm{i}}\right) /$ $\mathrm{E}\left(\mathrm{OD}_{\mathrm{i}}\right)$, where $\mathrm{OD}_{\mathrm{i}}$ and $\mathrm{L}_{\mathrm{i}}$ were the signal intensity and TRF length, respectively, at position i on the gel image. This method takes into account the greater intensity of signals from larger fragments. Briefly, the scanned image was divided into a grid consisting of $X$ columns and multiple rows where $X$ were the number of samples. The rows were positioned to cover the entire vertical length of the image. The vertical size of grid boxes was arbitrary but it was small enough such that many boxes overlaid a signal smear. Two rows above and two rows below each signal smear were used to calculate the background. The background OD was averaged and then subtracted from the OD of each grid box to give the signal due to TRFs at that position. For each sample, OD and L were computed for each grid box, where OD was the total signal intensity within a grid box and $\mathrm{L}$ was the distance (in $\mathrm{cm}$ ) at the mid-point of the grid box. Mean TRF length was then calculated using the above formula and values reported are the average of at least two independent Southern blots.

\section{ACKNOWLEDGMENTS}

Work in the corresponding authors' labs was supported by Department of Defense award W81XWH-06-1-0703, the National Institute of Health/ National Cancer Institute award R01-CA118975 and by the Department of Energy under Contract No. DE-
AC03-76SF00098 to Ruth Lupu and by grants from the Ministerio de Ciencia e Innovación (Grant SAF201238914), Plan Nacional de I+D+I, Spain and the Agència de Gestió d'Ajuts Universitaris i de Recerca (AGAUR) (Grant 2014 SGR229), Departament d'Economia I Coneixement, Catalonia, Spain to Javier A. Menendez.

\section{CONFLICTS OF INTEREST}

There is no conflict of interest.

\section{REFERENCES}

1. de Lange T. Protection of mammalian telomeres. Oncogene. 2002; 21:532-540.

2. Smogorzewska A, de Lange T. Regulation of telomerase by telomeric proteins. Annu Rev Biochem. 2004; 73:177-208.

3. Liu D, O'Connor MS, Qin J, Songyang Z. Telosome, a mammalian telomere-associated complex formed by multiple telomeric proteins. J Biol Chem. 2004; 279:5133851342.

4. de Lange T. Shelterin: the protein complex that shapes and safeguards human telomeres. Genes Dev. 2005; 19:21002110 .

5. Colgin L, Reddel R. Telomere biology: a new player in the end zone. Curr Biol. 2004; 14:R901-R902.

6. Xin H, Liu D, Songyang Z. The telosome/shelterin complex and its functions. Genome Biol. 2008; 9:232.

7. Songyang Z, Liu D. Inside the mammalian telomere interactome: regulation and regulatory activities of telomeres. Crit Rev Eukaryot Gene Expr. 2006; 16:103-118.

8. Wan M, Qin J, Songyang Z, Liu D. OB fold-containing protein 1 (OBFC1), a human homolog of yeast Stn1, associates with TPP1 and is implicated in telomere length regulation. J Biol Chem. 2009; 284:26725-26731.

9. Lupu R, Colomer R, Zugmaier G, Sarup J, Shepard M, Slamon D and Lippman ME. Direct interaction of a ligand for the erbB2 oncogene product with the EGF receptor and p185erbB2. Science. 1990; 249:1552-1555.

10. Holmes WE, Sliwkowski MX, Akita RW, Henzel WJ, Lee J, Park JW, Yansura D, Abadi N, Raab H, Lewis GD, et al. Identification of heregulin, a specific activator of p185erbB2. Science. 1992; 256: 1205-1210.

11. Alroy I, Yarden Y. The ErbB signaling network in embryogenesis and oncogenesis: signal diversification through combinatorial ligand-receptor interactions. FEBS Lett. 1997; 410:83-86.

12. Pinkas-Kramarski R, Alroy I, Yarden Y. ErbB receptors and EGF-like ligands: cell lineage determination and oncogenesis through combinatorial signaling. J Mammary Gland Biol Neoplasia. 1997;2:97-107.

13. Citri A, Yarden Y. EGF-ERBB signalling: towards the systems level. Nat Rev Mol Cell Biol. 2006; 7:505-516.

14. Tang CK, Perez C, Grunt T, Waibel C, Cho C and Lupu 
R. Involvement of heregulin-beta2 in the acquisition of the hormone-independent phenotype of breast cancer cells. Cancer Res. 1996; 56: 3350-3358.

15. Atlas E, Cardillo M, Mehmi I, Zahedkargaran H, Tang C and Lupu R. Heregulin is sufficient for the promotion of tumorigenicity and metastasis of breast cancer cells in vivo. Mol Cancer Res. 2003; 1:165-175.

16. Tsai MS, Shamon-Taylor LA, Mehmi I, Tang CK and Lupu R. Blockage of heregulin expression inhibits tumorigenicity and metastasis of breast cancer. Oncogene. 2003; 22: 761768.

17. Harris LN, Yang L, Tang C, Yang D, Lupu R. Induction of sensitivity to doxorubicin and etoposide by transfection of MCF-7 breast cancer cells with heregulin beta-2. Clin Cancer Res 1998; 4: 1005-1012.

18. Atlas E, Bojanowski K, Mehmi I and Lupu R. A deletion mutant of heregulin increases the sensitivity of breast cancer cells to chemotherapy without promoting tumorigenicity. Oncogene. 2003; 22: 3441-3451.

19. Menendez JA, Mehmi I and Lupu R. Heregulin-triggered Her-2/neu signaling enhances nuclear accumulation of p21WAF1/CIP1 and protects breast cancer cells from cisplatin-induced genotoxic damage. Int J Oncol. 2005; 26: 649-659.

20. Li W, Park JW, Nuijens A, Sliwkowski MX and Keller GA. Heregulin is rapidly translocated to the nucleus and its transport is correlated with c-myc induction in breast cancer cells. Oncogene 1996; 12: 2473-2477.

21. Golding M, Ruhrberg C, Sandle J, Gullick WJ. Mapping nucleolar and spliceosome localization sequences of neuregulin1-beta3. Exp Cell Res. 2004; 299:110-118.

22. Marshall C, Blackburn E, Clark M, Humphreys S, Gullick WJ. Neuregulins 1-4 are expressed in the cytoplasm or nuclei of ductal carcinoma (in situ) of the human breast. Breast Cancer Res Treat. 2006; 96:163-168.

23. Breuleux M, Schoumacher F, Rehn D, Kung W, Mueller $\mathrm{H}$ and Eppenberger U. Heregulins implicated in cellular functions other than receptor activation. Mol Cancer Res. 2006; 4: 27-37.

24. O'Connor MS, Safari A, Liu D, Qin J, Songyang Z. The human Rap1 protein complex and modulation of telomere length. J Biol Chem. 2004;279:28585-28591.

25. Arat NÖ, Griffith JD. Human Rap1 interacts directly with telomeric DNA and regulates TRF2 localization at the telomere. J Biol Chem. 2012; 287:41583-41594

26. Janoušková E, Nečasová I, Pavloušková J, Zimmermann M, Hluchý M, Marini V, Nováková M, Hofr C. Human Rap1 modulates TRF2 attraction to telomeric DNA. Nucleic Acids Res. 2015; 43:2691-2700.

27. Li X, Liu W, Wang H, Yang L, Li Y, Wen H, Ning H, Wang J, Zhang L, Li J, Fan D. Rap1 is indispensable for TRF2 function in etoposide-induced DNA damage response in gastric cancer cell line. Oncogenesis. 2015; 4:e144.

28. Quina AS, Parreira L. Telomere-surrounding regions are transcription-permissive 3D nuclear compartments in human cells. Exp Cell Res. 2005; 307:52-64.

29. Li B, Oestreich S, de Lange T. Identification of human Rap1: implications for telomere evolution. Cell. 2000; 101:471-483.

30. Li B, de Lange T. Rap1 affects the length and heterogeneity of human telomeres. Mol Biol Cell. 2003; 14:5060-5068.

31. Menendez, JA, Rubio MA, Benboudjema L, Campisi J, Lupu R. Heregulin, a new regulator of telomere length in human cells. Oncotarget 2015 (in press)

32. Keresztes M, Boonstra J. Import(ance) of growth factors in(to) the nucleus. J Cell Biol. 1999; 145:421-424.

33. Prochiantz A, Théodore L. Nuclear/growth factors. Bioessays. 1995; 17:39-44.

34. Bryant DM, Stow JL. Nuclear translocation of cell-surface receptors: lessons from fibroblast growth factor. Traffic. 2005; 6:947-954.

35. Wells A, Marti U. Signalling shortcuts: cell-surface receptors in the nucleus? Nat Rev Mol Cell Biol. 2002; 3:697-702.

36. Ferrer-Soler L, Vazquez-Martin A, Brunet J, Menendez JA, De Llorens R, Colomer R. An update of the mechanisms of resistance to EGFR-tyrosine kinase inhibitors in breast cancer: Gefitinib (Iressa) -induced changes in the expression and nucleo-cytoplasmic trafficking of HERligands (Review). Int J Mol Med. 2007; 20:3-10.

37. Campisi J, Kim SH, Lim CS, Rubio M. Cellular senescence, cancer and aging: the telomere connection. Exp Gerontol. 2001; 36:1619-1637.

38. Kim Sh SH, Kaminker P, Campisi J. Telomeres, aging and cancer: in search of a happy ending. Oncogene. 2002; 21:503-511.

39. Krtolica A, Campisi J. Integrating epithelial cancer, aging stroma and cellular senescence. Adv Gerontol. 2003; 11:109-116.

40. Campisi J. Senescent cells, tumor suppression, and organismal aging: good citizens, bad neighbors. Cell. 2005; 120:513-522.

41. Krtolica A, Parrinello S, Lockett S, Desprez PY, Campisi J. Senescent fibroblasts promote epithelial cell growth and tumorigenesis: a link between cancer and aging. Proc Natl Acad Sci U S A. 2001; 98:12072-12077.

42. Krtolica A, Campisi J. Cancer and aging: a model for the cancer promoting effects of the aging stroma. Int J Biochem Cell Biol. 2002; 34:1401-1414.

43. Parrinello S, Coppe JP, Krtolica A, Campisi J. Stromalepithelial interactions in aging and cancer: senescent fibroblasts alter epithelial cell differentiation. J Cell Sci. 2005; 118:485-496.

44. Linskens MH, Feng J, Andrews WH, Enlow BE, Saati SM, Tonkin LA, Funk WD, Villeponteau B. Cataloging altered gene expression in young and senescent cells using enhanced differential display. Nucleic Acids Res. 1995; 23:3244-3251. 
45. Blasco MA. Telomeres and human disease: ageing, cancer and beyond. Nat Rev Genet. 2005; 6:611-622.

46. Muñoz P, Blanco R, Flores JM, Blasco MA. XPF nucleasedependent telomere loss and increased DNA damage in mice overexpressing TRF2 result in premature aging and cancer. Nat Genet. 2005; 37:1063-1071.

47. Muñoz P, Blanco R, Blasco MA. Role of the TRF2 telomeric protein in cancer and ageing. Cell Cycle. 2006; 5:718-721.

48. Meeker AK, Argani P. Telomere shortening occurs early during breast tumorigenesis: a cause of chromosome destabilization underlying malignant transformation? J Mammary Gland Biol Neoplasia. 2004; 9:285-296.

49. Chin K, de Solorzano CO, Knowles D, Jones A, Chou W, Rodriguez EG, Kuo WL, Ljung BM, Chew K, Myambo K, Miranda M, Krig S, Garbe J, et al. In situ analyses of genome instability in breast cancer. Nat Genet. 2004; 36:984-948.

50. Griffith JK, Bryant JE, Fordyce CA, Gilliland FD, Joste NE, Moyzis RK. Reduced telomere DNA content is correlated with genomic instability and metastasis in invasive human breast carcinoma. Breast Cancer Res Treat. 1999; 54:59-64.

51. Meeker AK, Hicks JL, Gabrielson E, Strauss WM, De Marzo AM, Argani P. Telomere shortening occurs in subsets of normal breast epithelium as well as in situ and invasive carcinoma. Am J Pathol. 2004; 164:925-935.

52. Dunn M, Sinha P, Campbell R, Blackburn E, Levinson N, Rampaul R, Bates T, Humphreys S, Gullick WJ. Coexpression of neuregulins 1, 2, 3 and 4 in human breast cancer. J Pathol. 2004; 203:672-680

53. Marx J. Telomeres. Chromosome end game draws a crowd. Science. 2002; 295:2348-2351.

54. O'Connor MS, Safari A, Xin H, Liu D, Songyang Z. A critical role for TPP1 and TIN2 interaction in high-order telomeric complex assembly. Proc Natl Acad Sci U S A. 2006; 103:11874-11879.

55. Doksani Y, Wu JY, de Lange T, Zhuang X. Superresolution fluorescence imaging of telomeres reveals TRF2dependent T-loop formation. Cell. 2013; 155:345-356. 